Advances in Gene Technology: The Genome and Beyond -

Structural Biology for Medicine (Proceedings of the 2002 Miami

Nature Biotechnology Winter Symposium)

TheScientificWorld 2002, 2(S2), 87-88

ISSN 1532-2246; DOI 10.1100/tsw.2002.41

\title{
THE MAMMALIAN CELL AS A MACROMOLECULAR ASSEMBLY
}

Murray P. Deutscher, Alice Hudder, Lubov Nathanson, and Romualdas Stapulionis Department of Biochemistry and Molecular Biology, University of Miami School of Medicine, P.O. Box 016139, Miami FL 33101 mdeutsch@med.miami.edu

INTRODUCTION. Throughout much of the history of biochemistry a reductionist approach has dominated attempts to understand cell function[1]. While such studies have been essential for identifying cell components and determining their catalytic and structural properties, by necessity, this approach destroys the structural organization that distinguishes a living cell from a test tube containing the same components. In recent years, it has become evident that interactions among macromolecules play an important role in the efficiency of cellular metabolism, and various methodologies have been employed to study such interactions. We have been investigating the mammalian protein synthetic machinery as a model system to understand the importance of structural organization for in vivo cell function.

METHODS. Chinese hamster ovary cells, permeabilized with the plant glycoside, saponin, were used to measure protein synthesis and to study leakage of macromolecular components. These cells retain much of the structural organization of living cells.

RESULTS. Protein synthesis in permeabilized cells proceeds at rates approaching those of intact cells, and is many times higher that that of usual cell-free systems[2]. Efficient protein synthesis in permeabilized cells requires the addition of $\mathrm{K}^{+}, \mathrm{Mg}^{2+}$, and creatine phosphate, but macromolecular components are retained within the cell and do not have to be supplied from the outside. As observed with intact cells, aminoacyl-tRNA is channeled in this system, being directly transferred from one component of the translation system to the next, but is absent from the cell fluid where it could leak from the permeabilized cell. Disruption of the microfilament, but not the microtubule, network of the cell, dramatically decreases protein synthesis and leads to leakage of aminoacyl-tRNA and a variety of other translation components. Extension of these studies to other cellular macromolecules reveals that they behave similarly to the translation machinery.

DISCUSSION. Based on simple experiments monitoring leakage from permeabilized cells, we conclude that the protein synthetic machinery, and other macromolecules as well, are sequestered within cells and do not diffuse in the cell fluid. The cytoskeletal network plays an important role in maintaining the structural organization of the cell. The data suggest that the majority of macromolecules are directly or indirectly bound to cytoskeletal (and membranous) elements within cells, and probably move by motor-driven processes, rather than by diffusion. 
ACKNOWLEDGMENT. This work was supported by Grant GM16317 from the National Institutes of Health.

\section{REFERENCES}

1. Srere, P. (2000) Trends Biochem. Sci. 25, 150-153.

2. Deutscher, M.P. (2000) in Technological and Medical Implications of Metabolic Control Analysis. Cornish-Bowden, A.J. and Cardenas, M.L., Eds. Kluwer Publishers, Dordrecht, Netherlands. pp. 215-221. 

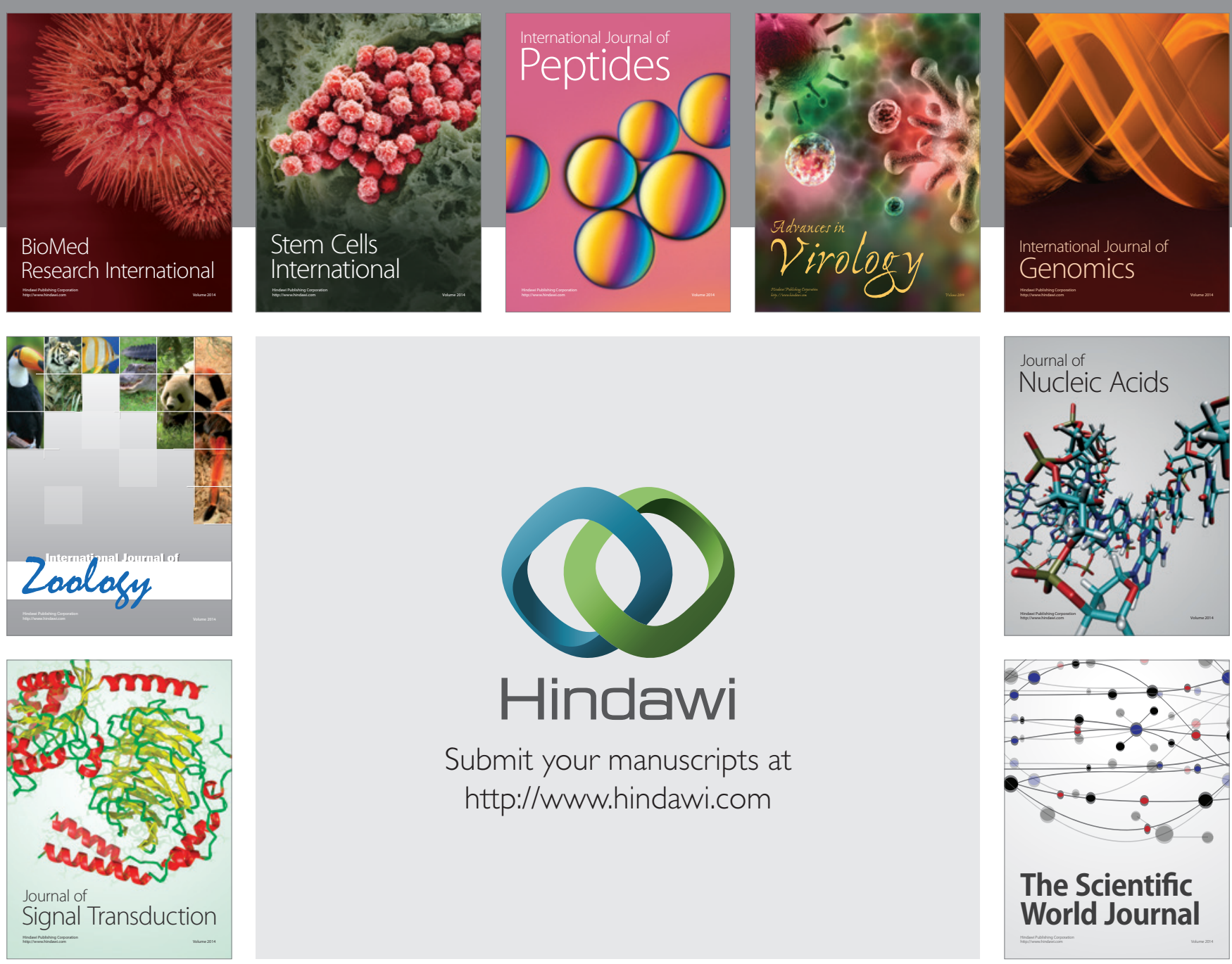

Submit your manuscripts at

http://www.hindawi.com
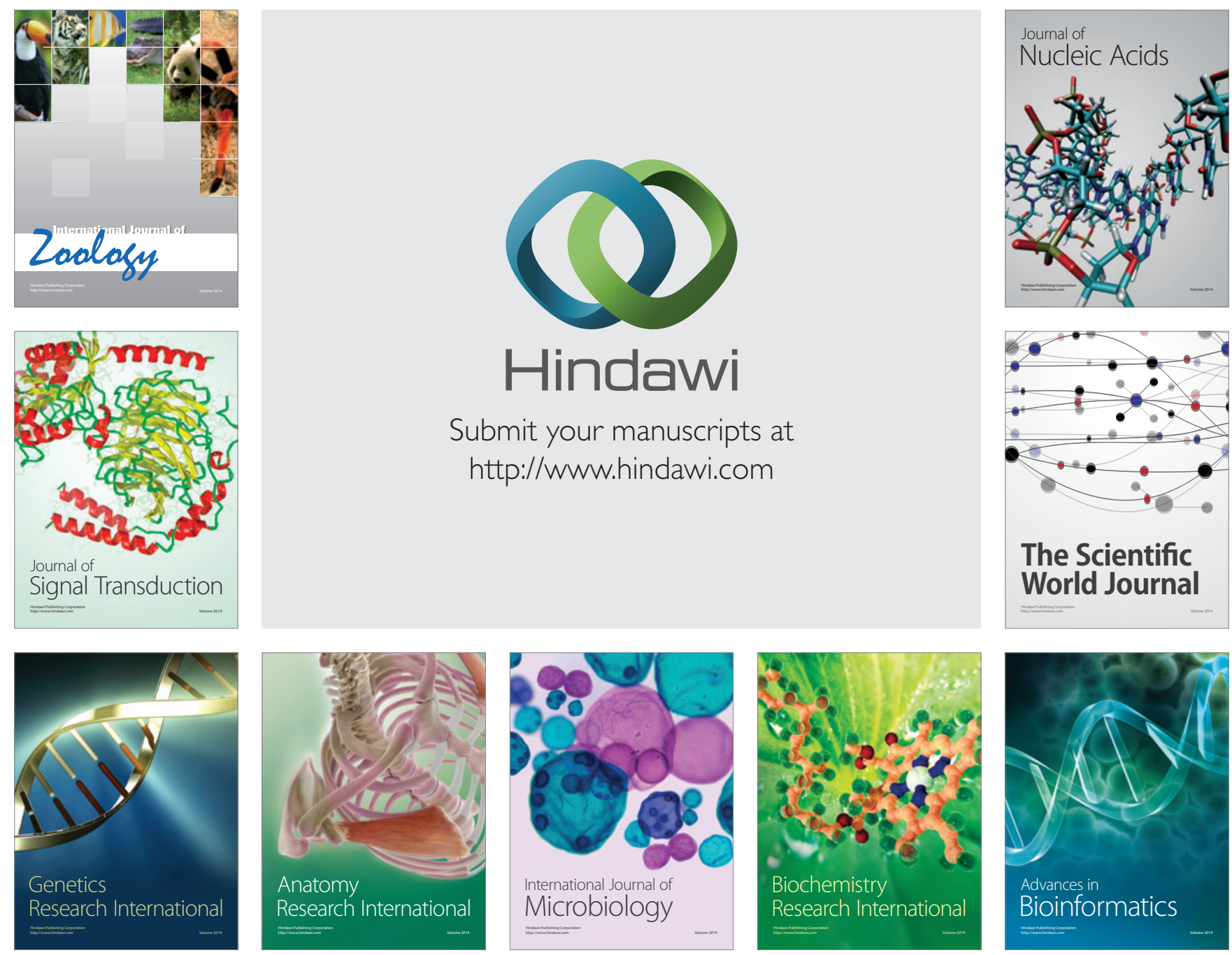

The Scientific World Journal
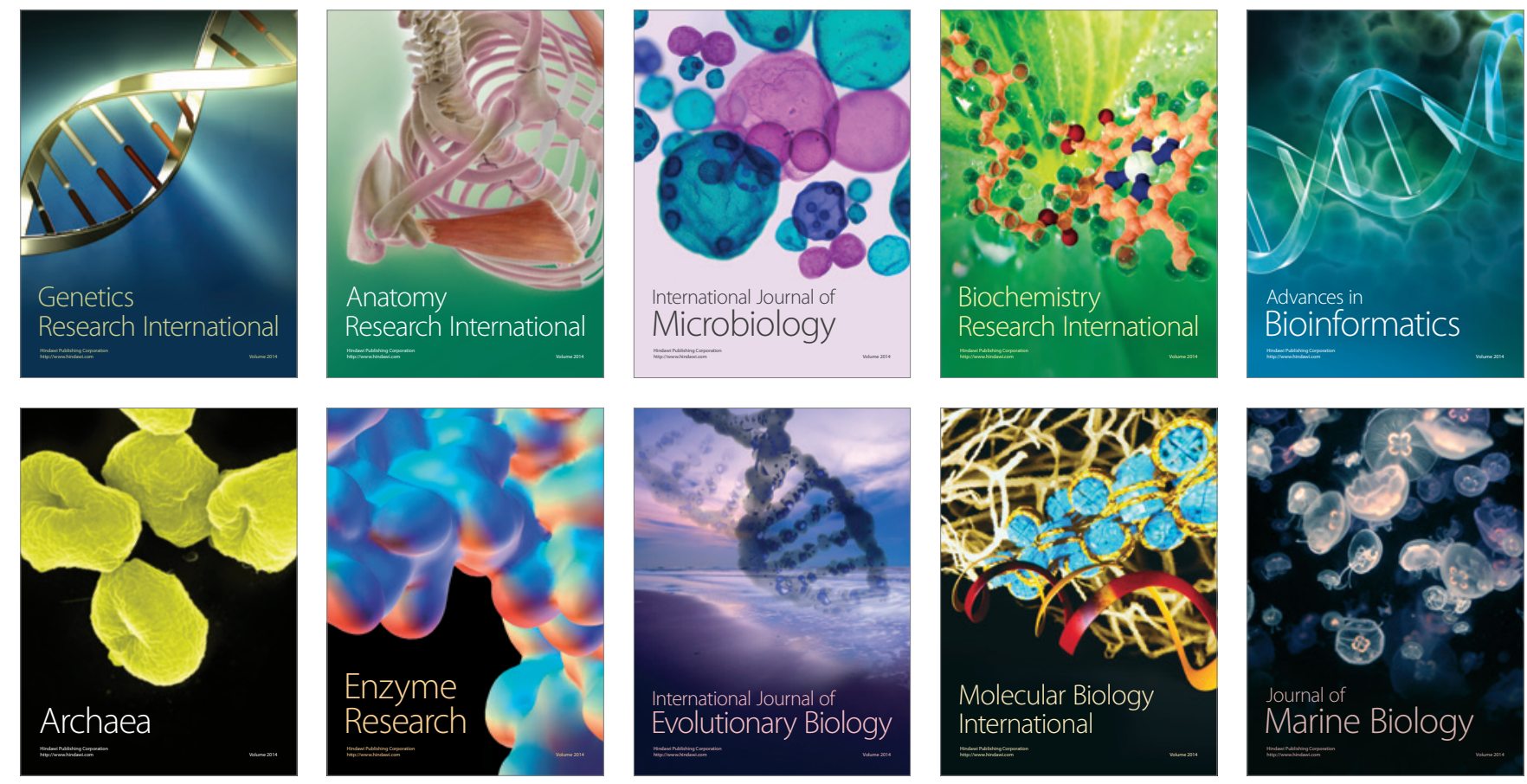